\title{
To Enhance the Power Stability Using Fuzzy Logic
}

\author{
Krishan Kumar ${ }^{1}$, Niranjan Kumar ${ }^{2}$, Rajnish Mitter ${ }^{3}$ \\ ${ }^{1,2}$ Research Scholar,EEE Deptt., BRCMCET, Bahal, Bhiwani, Haryana, India \\ ${ }^{3}$ Associate Prof., EEE Deptt. BRCMCET, Bahal, Bhiwani, Haryana, India
}

\begin{abstract}
This paper describes the design of a Fuzzy logic based controller to counter the small instability in power system. The stabilizing signal is computed in real time using suitable fuzzy membership functions depending upon the state of the power factor. The use of output membership function permits further fine tuning of the controller parameters for varied system configurations especially in multi machine environment. The efficacy of the proposed stabilizing technique has been demonstrated using multi-machine computer simulation model of power system under a wide range of system and test conditions.
\end{abstract}

Keywords: Capacitor bank, Power System Stabilizer (PSS, Fuzzy Logic Controller (FLC).

\section{INTRODUCTION}

As inductive load goes on increasing on three phase power system the power factor of line which is given by 'Cos $\Phi$ ' also get increased. Here in this research paper a scheme is provided where shunt capacitor banks are used to improve the power factor. A number of different shunt capacitor banks will be used in this proposed in this project. Only a fixed number of capacitor banks will be used at a time based on the requirement. To switch the capacitor banks ON a thyristor based switch will be used. The switching of the thyristor will be controlled by the fuzzy logic controller.

\section{Structure Modelling}

The modelling of this system will be done in fuzzy toolbox of MATLAB. The FIS editor of this particular toolbox is used to model the structure as shown.

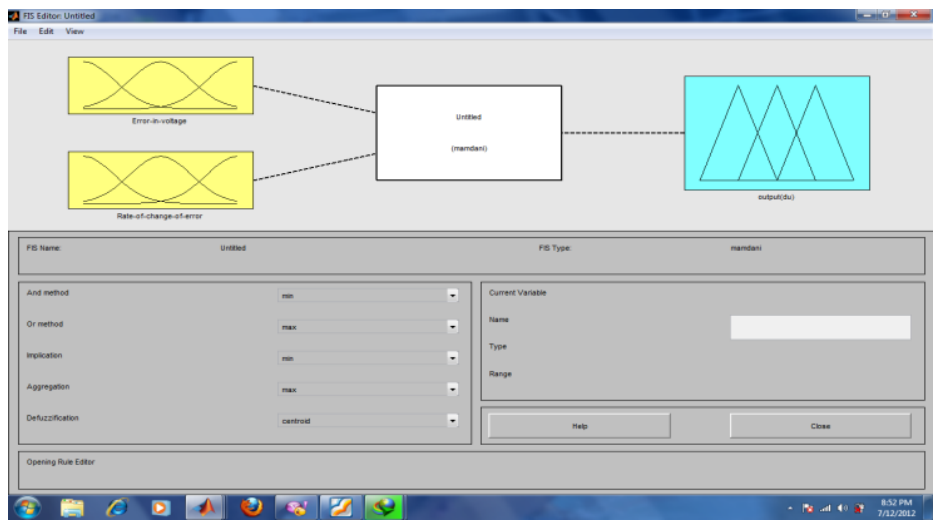

Here are 2 inputs and one output in the structure as shown in FIS editor. The next thing to be done is defining the membership functions for all the input and output variables. This will be done in the membership editor as shown.

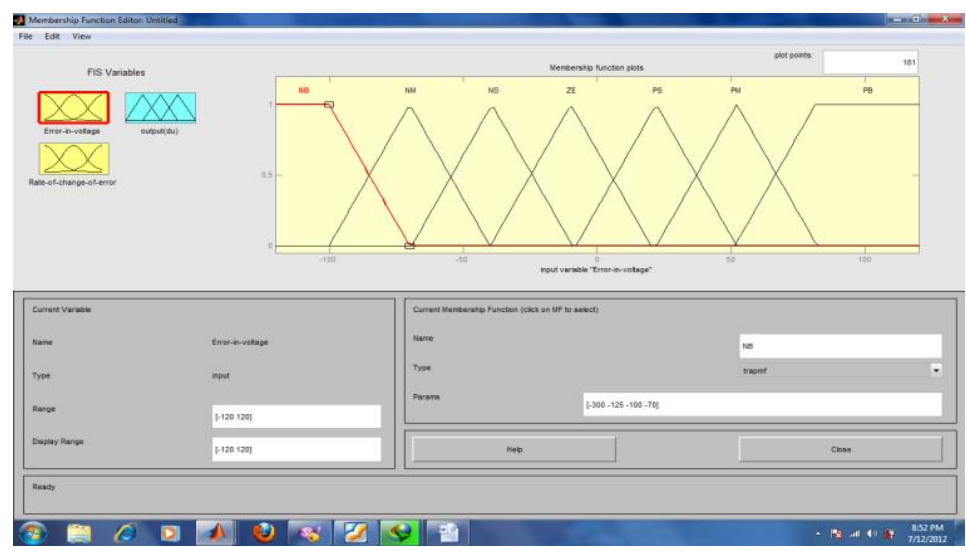

www.iosrjournals.org 
To enhance the power stability using Fuzzy Logic
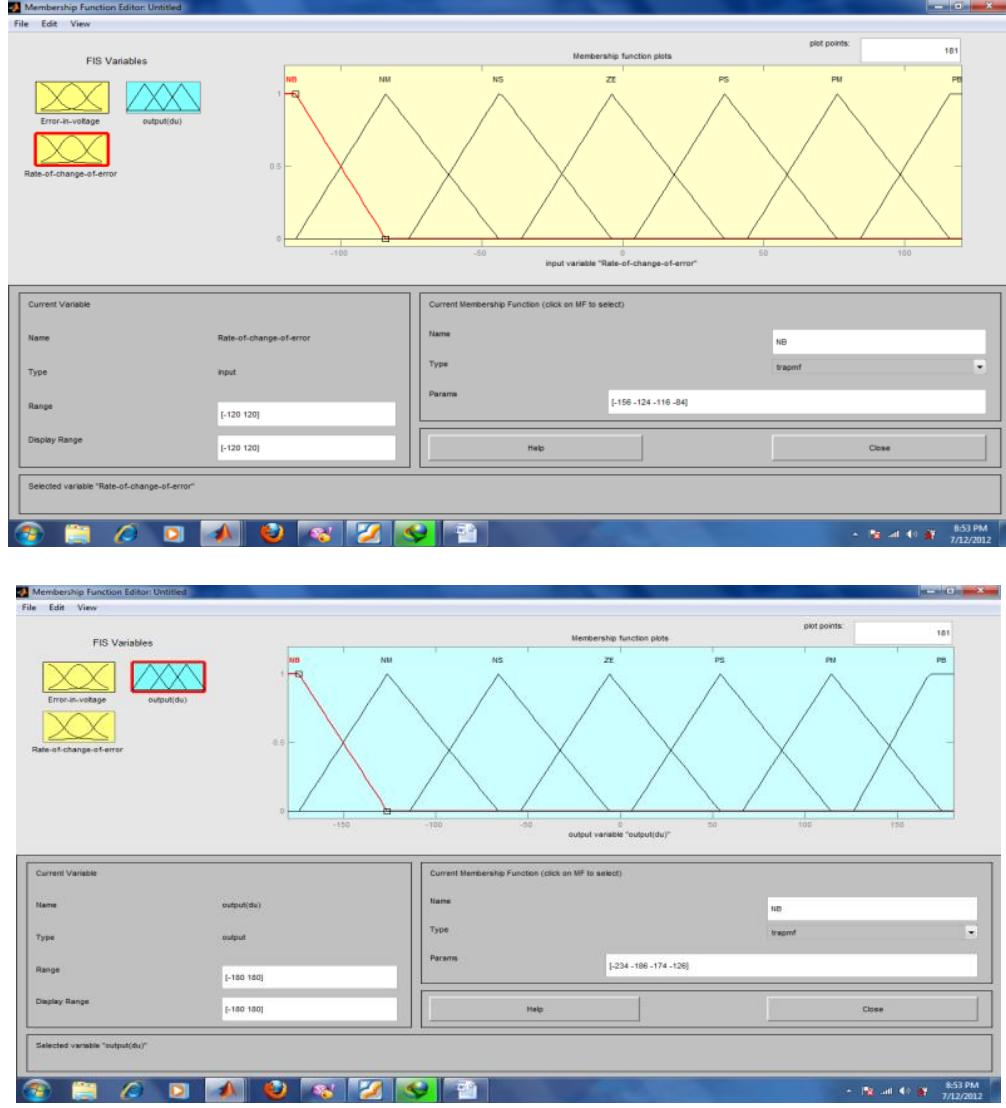

The rule editor will used to format the rules using different combinations of input variables as shown.

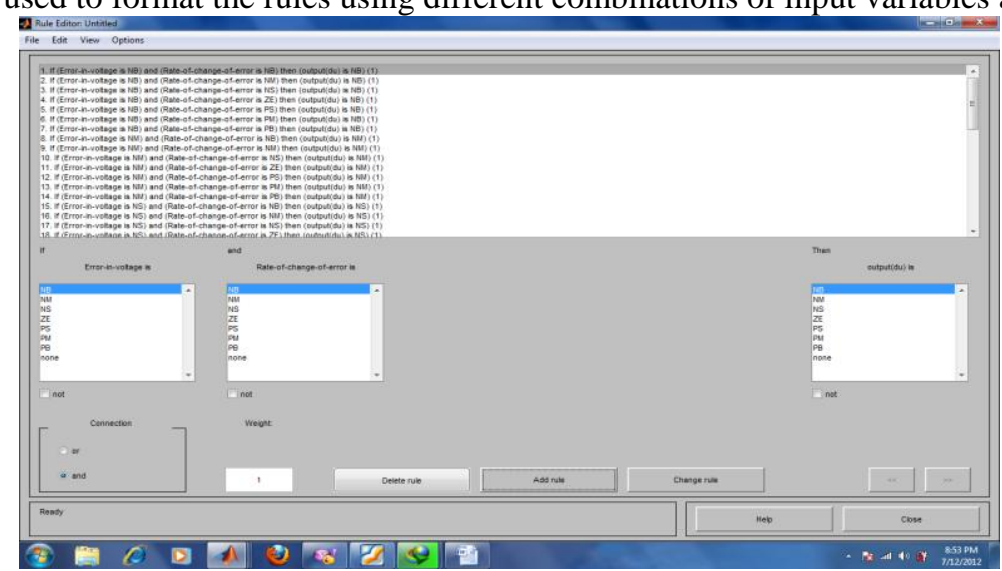

III. Results

The rule viewer showing the rules formatted for the control of capacitor bank switching on X-Y plane as shown.

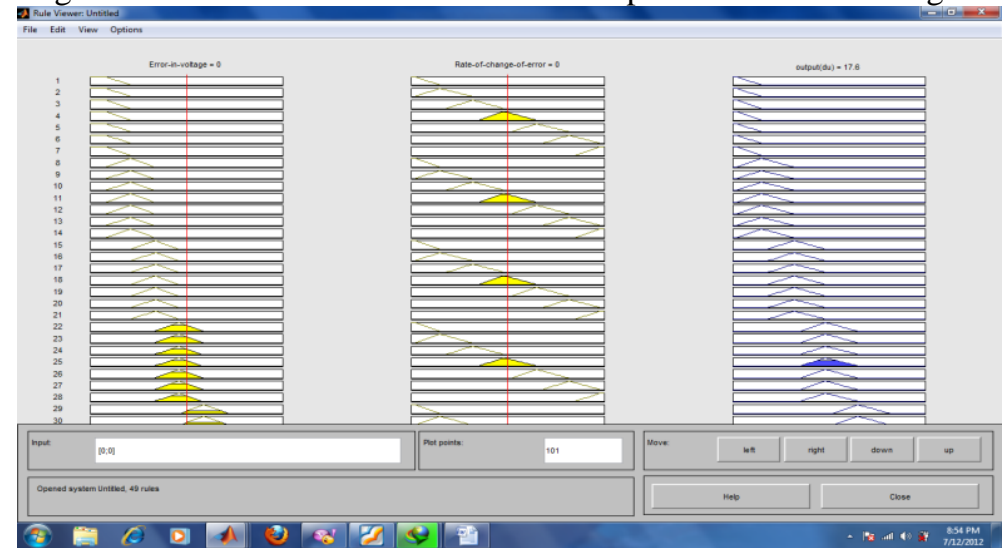


The performance on $3 \mathrm{D}$ plane is as shown in the surface viewer.

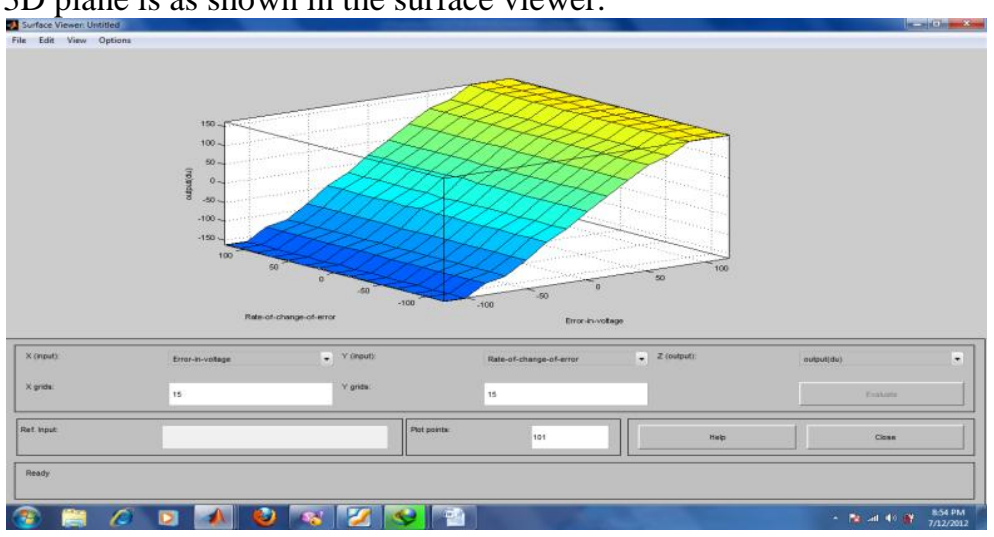

\section{REFERENCES}

[1]. Fuzzy Logic based Robust Power System Stabilizer for Multi-Machine Power System. This paper appears in: Industrial Technology, 2006. ICIT 2006. IEEE International Conference on Date of Conference: 15-17 Dec. 2006 Author(s): Gupta, R. Eng. Coll., Kota Sambariya, D.K. ; Gunjan, R. Page(s):1037-1042

[2]. Design of Genetic Algorithm Based Fuzzy Logic Power System Stabilizers in Multimachine Power System. This paper appears in: Power System Technology and IEEE Power India Conference, 2008. POWERCON 2008. Joint International Conference onDate of Conference: 12-15 Oct. 2008Author(s): Dubey, M. Dept. of Electr. Eng., Maulana Azad Nat. Inst. of Technol., Bhopal Page(s):1- 6 .

[3]. A simple fuzzy excitation control system for synchronous generator . This paper appears in: Emerging Trends in Electrical and Computer Technology (ICETECT), 2011 International Conference on Date of Conference: 23-24 March 2011Author(s): Ramya, R. Dept. of EEE, Thiagarajar Coll. of Eng., Madurai, India Selvi, K. Page(s): 35 - 39

[4]. Performance of A Fuzzy Power System Stabilizer With Tie Line Active Power Deviation Feedback. This paper appears in: Power Systems Conference and Exposition, 2006. PSCE '06. 2006 IEEE PES Date of Conference: Oct. 29 2006-Nov. 12006 Author(s): Mitra, P. Dept. of Electr. Eng., Jadavpur Univ., Calcutta Chowdhury, S. ; Chowdhury, S.P. ; Pal, S.K. ; Lahiri, R.N. ; Song, Y.H. Page(s): 884 - 889

[5]. Velocity relaxed swarm intelligent tuning of fuzzy based power system stabilizer. This paper appears in: Power India Conference, 2006 IEEE Date of Conference: 0-0 0 Author(s): Mukherjee, V. Dept. of Electr. Eng., Asansol Eng. Coll. Ghoshal, S.P.

[6]. Comparison of Robust Fuzzy Logic and Fast output sampling feedback based Power System Stabilizer for SMIB This paper appears in: Industrial Technology, 2006. ICIT 2006. IEEE International Conference on Date of Conference: 15-17 Dec. 2006 Author(s): Gupta, R. Eng. Coll., Kota Bhatia, D. Page(s): 1031 - 1036

[7]. MATLAB simulink model of fuzzy logic controller with PSS and its performance analysis. This paper appears in: Advances in Engineering, Science and Management (ICAESM), 2012 International Conference on Date of Conference: 30-31 March 2012 Author(s): Gowrishankar, K. Department of ECE, Dr. Paul's Engineering College, Anna University, INDIA Masud Khan, M.D. Page(s): 541 - 550

[8]. Design of differential evolution algorithm-based robust fuzzy logic power system stabilizer using minimum rule base, This paper appears in:Generation, Transmission \& Distribution, IETDate of Publication: February 2012Author(s): Vakula, V.S. Dept. of EEE, JNT Univ., Kakinada, India Sudha, K.R. Volume: 6 , Issue: 2 Page(s): 121 - 132

[9]. Synthetic Application of FPSS and TCSC for Improvement Of Voltage and Current Profiles in Electrical Power Systems. This paper appears in: Industrial Electronics and Applications, 2006 1ST IEEE Conference on Date of Conference: 24-26 May 2006 Author(s): Kazemi, A. Dept. of Electr. Eng., Iran Univ. of Sci. \& Technol., Tehran Mousavi, S.M.G. ; Kalantar, M. Page(s): $1-6$

[10]. Neurofuzzy Power System Stabilizer. This paper appears in: Energy Conversion, IEEE Transactions on Date of Publication: Sept. 2008 Author(s): Chaturvedi, D.K. Fac. Of Eng., Dept. of Electr. Eng., Dayalbagh Educ. Inst., Agra Malik, O.P. Volume: 23, Issue:3Page(s):887-894 